\title{
INVESTIGATION INTO THE REGIOCHEMISTRY OF SOME PYRAZOLES DERIVED FROM 1, 3-DIPOLAR CYCLOADDITION OF ACRYLONITRILE WITH SOME NITRILIMINES: THEORETICAL AND EXPERIMENTAL STUDIES
}

\author{
FARID MOEINPOUR ${ }^{*}$, MEHDI BAKAVOLI ${ }^{2}$, ABOLGHASEM DAVOODNIA ${ }^{2}$ and ALI MORSALI ${ }^{2}$ \\ ${ }^{1}$ Department of Chemistry, Islamic Azad University-Bandar Abbas Branch, Bandar Abbas, Iran \\ ${ }^{2}$ Department of Chemistry, Islamic Azad University-Mashhad Branch, Mashhad, Iran
}

(Received: January 12, 2011 - Accepted: September 7, 2011)

\begin{abstract}
1,3-dipolar cycloaddition between acrylonitrile and two N-(4-substituted)phenyl-C-(4-chlorophenyl)nitrilimines which were generated in situ afforded the new pyrazoles. The regiochemistry and reactivity of these reactions has been investigated on the basis of density functional theory (DFT) -based reactivity indexes and activation energy calculations. The theoretical ${ }^{13} \mathrm{C}$ NMR chemical shifts of the cycloadducts which were obtained by GIAO method were comparable with the observed values.
\end{abstract}

\section{INTRODUCTION}

1,3-Dipolar cycloaddition reactions of nitrilimines with dipolarophiles containing a carbon-carbon double bond represent an important synthetic route to substituted pyrazoles and pyrazolidines ${ }^{1}$. These reactions are one of the most important processes with both synthetic and mechanistic interest in organic chemistry ${ }^{2}$. Current understanding of the underlying principles in the Diels-Alder (DA) reactions and the 1,3-DCs has grown from a fruitful interplay between theory and experiment ${ }^{2-4}$. Two major factors i.e. the steric and electronic effects can influence the regioselectivity of these reactions ${ }^{2}$. Although transition state theory remains the most widely used and the most rigorous approach for the study of the mechanism and the regiochemistry of these reactions, the localization of transition states is not always easier. Furthermore, transition state calculations are often very time-consuming when bulky substituents are present in reactive systems. Recently, reactivity descriptors based on the density functional theory (DFT), such as Fukui indexes, local softnesses and local electrophilicity, have been extensively used for the prediction of the regioselectivity. For instance, several treatments of 1,3-DC reactions of nitrilimines with various dipolarophiles can be found in the literature ${ }^{5-8}$. In this context, we became interested in the reactivity of acrylonitrile 3 as dipolarophile towards two N-(4-substituted)phenyl-C-(4chlorophenyl)nitrilimines $\mathbf{2}$ as dipoles which were generated in situ by base treatment of the corresponding hydrazonoyl chlorides $\mathbf{1}$ in order to synthesize the new 3-(4-chlorophenyl)-1-(4-nitrophenyl)-4,5-dihydro-1H-pyrazole-4carbonitrile $4 \mathbf{a}$ and 1-(4-bromophenyl)-3-(4-chlorophenyl)-4,5-dihydro- $1 \mathrm{H}$ pyrazole-5-carbonitrile $\mathbf{5 b}$ (Scheme1). In addition, we found it worthwhile to analyze the regioselectivity of these 1,3 -DC reactions by several theoretical approaches, namely, activation energy calculations and DFT-based reactivity indexes. Finally, the gauge-invariant atomic orbital (GIAO) method ${ }^{9}$ was used to calculate NMR chemical shifts, to help the experimental cycloadduct determination, because it has shown to yield data comparable to those of the experiment ${ }^{10}$.

Regioselectivity criteria for two-center reactions

According to the model recently proposed by Domingo ${ }^{11,12}$, the regioselectivity of a polar cycloaddition reaction could be explained by the most favorable two-center interactions between the highest nucleophilic and electrophilic sites of the reagents. The corresponding reaction channel favors the maximum CT from the nucleophilic to the electrophilic reagent in the course of the polar cycloaddition reaction. Local electrophilicity and nucleophilicity indexes ${ }^{13-15}$ (for definition, see Eqs. 6 and 7) are expected to be useful descriptor of regional electrophilicity/nucleophilicity patterns that may account for the observed regioselectivity in two-center reactions with a significant polar character.

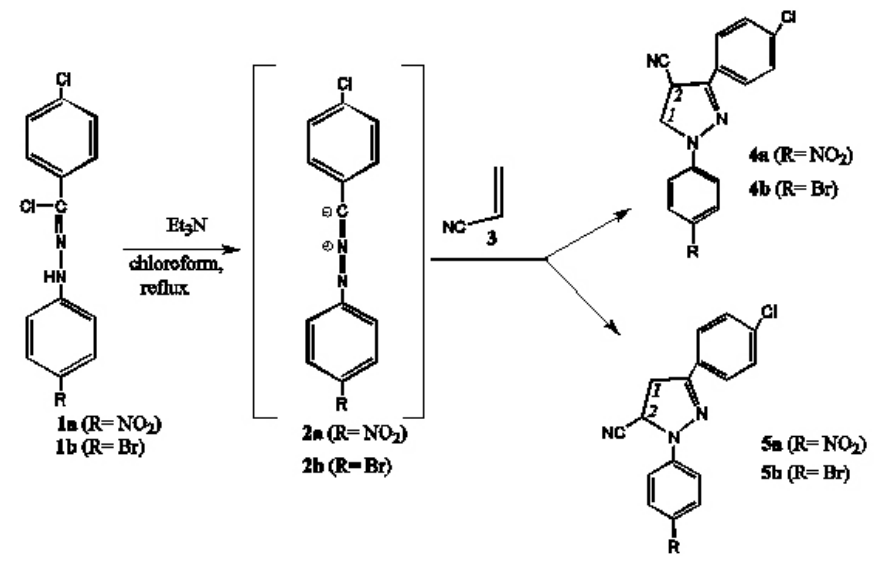

Scheme 1. The regioisomeric pathways for $1,3-\mathrm{DC}$ of nitrilimines 2 and dipolarophile 3.

\section{COMPUTATIONAL DETAILS}

All calculations were performed with the Gaussian98 program suite ${ }^{16}$. For DFT calculations, the B3LYP/6-31G (d) level of theory was employed. The optimizations of equilibrium geometries of reactants and products were performed using the Berny analytical gradient optimization method ${ }^{17}$. The transition states (TSs) for the 1,3-DC reactions have been localized at the B3LYP/6-31G (d) level of theory. The stationary points were characterized by frequency calculations in order to verify that the TSs had one and only one imaginary frequency.The atomic electronic populations were evaluated according to Merz-Kollman scheme (MK option) ${ }^{18,19}$. The global electrophilicity w for dipoles and dipolarophile was evaluated using Eq. (1) ${ }^{20}$ :

$$
\omega=\mu^{2} / 2 \eta
$$

In Eq. (1) $\mu$ and $\eta$ are the electronic chemical potential and the chemical hardness of the ground state (GS) of atoms and molecules, respectively.

The electronic chemical potential $\mu$ and chemical hardness $\eta$ were evaluated in terms of the one electron energies of the HOMO and LUMO, using Eqs. (2) and (3), respectively ${ }^{21,22:}$

$$
\mu \approx\left(\varepsilon_{H}+\varepsilon_{L}\right) / 2
$$




$$
\eta \approx\left(\varepsilon_{L}-\varepsilon_{H}\right)
$$

As usual, local indexes are computed in atomic condensed form ${ }^{23}$. The well-known Fukui function ${ }^{24,25}$ for electrophilic $\left(f_{\mathrm{k}}{ }^{-}\right)$and nucleophilic attack $\left(f_{\mathrm{k}}^{+}\right)$can be written as

$$
\begin{aligned}
& f_{k}^{-}=\left[\rho_{k}(N)-\rho_{k}(N-1]\right. \\
& f_{k}^{+}=\left[\rho_{k}(N+1)-\rho_{k}(N)\right]
\end{aligned}
$$

Where $\rho_{k}(\mathrm{~N}), \rho_{k}(\mathrm{~N}-1)$ and $\rho_{k}(\mathrm{~N}+1)$ are the gross electronic populations of the site $\mathrm{k}$ in neutral, cationic, and anionic systems, respectively.

The local electrophilicity index ${ }^{14}, \omega_{\mathrm{k}}$, condensed to atom $\mathrm{k}$ is easily obtained by projecting the global quantity onto any atomic center $\mathrm{k}$ in the molecule by using the electrophilic Fukui function (i.e. the Fukui function for nucleophilic attack, $f^{+}{ }_{k}{ }^{14}$ )

$$
\omega_{k}=\omega f_{k}^{+}
$$

Recently, Domingo et al. has introduced an empirical (relative) nucleophilicity index ${ }^{13}, \mathrm{~N}$, based on the HOMO energies obtained within the Kohn-Sham scheme ${ }^{22}$, and defined as $\mathrm{E}_{\text {номо }}(\mathrm{Nu})-\mathrm{E}_{\text {номо }}(\mathrm{TCE})$. This nucleophilicity scale is referred to tetracyanoethylene (TCE) taken as a reference. Local nucleophilicity index ${ }^{26}, \mathrm{~N}_{\mathrm{k}}$, was evaluated using the following equation ${ }^{26}$ :

$$
N_{k}=N f_{k}^{-}
$$

where $f_{k}^{-}$is the Fukui function for an electrophilic attack ${ }^{25}$.

The ${ }^{13} \mathrm{C}$ NMR chemical shifts were calculated by means of the GIAO method ${ }^{9}$, using the tetramethylsilane (TMS) as ${ }^{13} \mathrm{C}$ reference, at the $\mathrm{B} 3 \mathrm{LYP} / 6$ $311+\mathrm{G}$ (d) level of theory (reference value of ${ }^{13} \mathrm{C}=184.5307 \mathrm{ppm}$ ).

\section{EXPERIMENTAL}

The melting points were recorded on an Electrothermal type 9100 melting point apparatus. The ${ }^{1} \mathrm{H}$ NMR $(400 \mathrm{MHz})$ spectra were recorded on a Bruker AC 400 spectrometer. ${ }^{13} \mathrm{C}$ NMR spectra were determined using the Bruker $\mathrm{AM}-400$ instrument operating at $100 \mathrm{MHz}$. IR spectra were determined as $\mathrm{KBr}$ pellets on a Shimadzu model 470 spectrophotometer. The mass spectra were scanned on a Varian Mat CH-7 instrument at $70 \mathrm{eV}$. Hydrazonoyl chlorides (1) the precursors of nitrilimines (2) are known compounds and were prepared according to generally used methods ${ }^{27}$.

\section{Typical experimental procedure for $4 a$ and $5 b$}

To a solution of acrylonitrile $\mathbf{3}(5 \mathrm{mmol})$ and hydrazonoyl chlorides $\mathbf{1 a}, \mathbf{b}$ $(5 \mathrm{mmol})$ in chloroform $(20 \mathrm{ml})$ was added triethylamine $(0.7 \mathrm{ml}, 5 \mathrm{mmol})$. The reaction mixture was refluxed for $8-10 \mathrm{~h}$ till the hydrazonoyl chloride disappeared as indicated by TLC analysis. The solvent was evaporated and the residue was treated with methanol. The solid that formed was collected and crystallized from suitable solvent to afford the pure products $\mathbf{4 a}$ and $\mathbf{5 b}$ respectively in good yields.

3-(4-chlorophenyl)-1-(4-nitrophenyl)-4,5-dihydro-1H-pyrazole-4carbonitrile (4a): This compound was obtained as brown solid (90\%). m.p. $182{ }^{\circ} \mathrm{C}$. IR $(\mathrm{KBr})\left(\mathrm{n}_{\mathrm{max}} / \mathrm{cm}^{-1}\right): 1395,1493,1597 \mathrm{~cm}^{-1}$. MS (EI, $\left.70 \mathrm{eV}\right) \mathrm{m} / \mathrm{z}: 326$ $\left(\mathrm{M}^{+}\right), 328\left(\mathrm{M}^{+}+2\right)$. ${ }^{1} \mathrm{Hax}$ NMR $\left(400 \mathrm{MHz}, \mathrm{CDCl}_{3}\right) d_{H} 3.88(1 \mathrm{H}, \mathrm{d}, \mathrm{J}=16 \mathrm{~Hz}$, $\left.\mathrm{CH}_{\mathrm{A}} \mathrm{H}_{\mathrm{B}}\right), 4.01\left(1 \mathrm{H}, \mathrm{d}, \mathrm{J}=16 \mathrm{~Hz}, \mathrm{CH}_{\mathrm{A}} \mathrm{H}_{\mathrm{B}}\right), 5.92(1 \mathrm{H}, \mathrm{t}, \mathrm{CH}, \mathrm{J}=8 \mathrm{~Hz}), 7.39$ $(2 \mathrm{H}, \mathrm{dd}, \mathrm{CH}, \mathrm{J}=8 \mathrm{~Hz}, 4$-nitrophenyl ring), $7.58(2 \mathrm{H}, \mathrm{dd}, \mathrm{CH}, \mathrm{J}=8 \mathrm{~Hz}$, 4-chlorophenyl ring), $7.85(2 \mathrm{H}, \mathrm{dd}, \mathrm{CH}, \mathrm{J}=8 \mathrm{~Hz}$, 4-chlorophenyl ring), 8.27 $\left(2 \mathrm{H}, \mathrm{dd}, \mathrm{CH}, \mathrm{J}=8 \mathrm{~Hz}, 4\right.$-nitrophenyl ring). ${ }^{13} \mathrm{C}$ NMR $\left(100 \mathrm{MHz}, \mathrm{CDCl}_{3}\right) d_{c}$ $39.0(\mathrm{CH}), 48.7\left(\mathrm{CH}_{2}\right), 115.9(\mathrm{C} \equiv \mathrm{N}), 113.0,127.6,128.2,128.5,129.3,136.8$, 147.2 (C, phenyl rings), $149.9(\mathrm{C}=\mathrm{N})$. Anal. Calcd for $\mathrm{C}_{16} \mathrm{H}_{11} \mathrm{~N}_{4} \mathrm{O}_{2}: \mathrm{C}, 58.82$; H, 3.39; N, 17.15. Found: C, 58.85; H, 3.43; N, 17.19.

1-(4-bromophenyl)-3-(4-chlorophenyl)-4,5-dihydro-1H-pyrazole-5carbonitrile (5b): This compound was obtained as light pink solid (88\%). m.p. $165^{\circ} \mathrm{C}$. IR $(\mathrm{KBr})\left(\mathrm{n}_{\mathrm{max}} / \mathrm{cm}^{-1}\right): 1336,1558,1580 \mathrm{~cm}^{-1}$. MS (EI, $\left.70 \mathrm{eV}\right) \mathrm{m} / \mathrm{z}: 359$ $\left(\mathrm{M}^{+}\right), 361\left(\mathrm{M}^{+}+2\right), 363\left(\mathrm{M}^{+}+4\right) .{ }^{1} \mathrm{H}$ NMR $\left(400 \mathrm{MHz}, \mathrm{CDCl}_{3}\right) d_{\mathrm{H}} 3.64(1 \mathrm{H}, \mathrm{d}, \mathrm{J}$ $\left.=12 \mathrm{~Hz}, \mathrm{CH}_{\mathrm{A}} \mathrm{H}_{\mathrm{B}}\right), 3.66\left(1 \mathrm{H}, \mathrm{d}, \mathrm{J}=12 \mathrm{~Hz}, \mathrm{CH}_{\mathrm{A}} \mathrm{H}_{\mathrm{B}}\right), 4.98(1 \mathrm{H}, \mathrm{t}, \mathrm{CH}, \mathrm{J}=8 \mathrm{~Hz})$, $7.13(2 \mathrm{H}, \mathrm{dd}, \mathrm{CH}, \mathrm{J}=8 \mathrm{~Hz}, 4$-bromophenyl ring), $7.42(2 \mathrm{H}, \mathrm{dd}, \mathrm{CH}, \mathrm{J}=8 \mathrm{~Hz}$, 4-bromophenyl ring), 7.48 ( $2 \mathrm{H}$, dd, $\mathrm{CH}, \mathrm{J}=8 \mathrm{~Hz}$, 4-chlorophenyl ring), 7.64 $\left(2 \mathrm{H}, \mathrm{dd}, \mathrm{CH}, \mathrm{J}=8 \mathrm{~Hz}\right.$, 4-chlorophenyl ring), ${ }^{13} \mathrm{C} \mathrm{NMR}\left(100 \mathrm{MHz}, \mathrm{CDCl}_{3}\right), d_{\mathrm{C}}$ $38.8\left(\mathrm{CH}_{2}\right), 50.0(\mathrm{CH}), 116.7(\mathrm{C} \equiv \mathrm{N}), 114.1,115.1,127.3,129.1,132.2,135.9$, $142.5\left(\mathrm{C}\right.$, phenyl rings), $147.7(\mathrm{C}=\mathrm{N})$. Anal. Calcd for $\mathrm{C}_{16} \mathrm{H}_{11} \mathrm{Br} \mathrm{ClN}_{3}$ : C, 53.29; H, 3.07; N, 11.65. Found: C, 53.33; H, 3.09; N, 11.67).

\section{RESULTS AND DISCUSSION}

Nitrilimines 2 were generated in situ from base treatment of corresponding hydrazonoyl chlorides $\mathbf{1}$ by refluxing in chloroform. 1,3-DC of nitrilimines $\mathbf{2}$ with the dipolarophile proceeded smoothly in a selective manner to give a single regioisomer of each pair $\mathbf{4 a - 5 a}$ and $\mathbf{4 b}-\mathbf{5 b}$ in $90 \%$ and $88 \%$ yields respectively (scheme 1). For each one of these cycloaddition reactions, two cyclization modes have been investigated. They are related to the two regioisomeric approaching modes of nitrilimines $\mathbf{2}$ to the acrylonitrile $\mathbf{3}$ mentioned as $\mathbf{4 a}-\mathbf{5 a}$ and $\mathbf{4 b} \mathbf{- 5} \mathbf{5 b}$. The assignment of the regiochemistry of these products was based upon $i$ ) comparing the theoretical ${ }^{13} \mathrm{C}$ NMR spectral data obtained by GIAO method with the observed values for both regioisomers; $i$ ) activation energy calculations and iii) DFT-based reactivity indexes.

i) For further cycloadduct characterization, we obtained the theoretical ${ }^{13} \mathrm{C}$ chemical shifts values for the products through the GIAO method and compared it with the observed values. As it can be seen in Table 1 and Scheme 1 , the observed values for $\mathrm{C} 1$ and $\mathrm{C} 2$ in each of the isolated products (48.7 and 39.0, 38.8 and $50.0 \mathrm{ppm}$ in compounds $\mathbf{4}$ and $\mathbf{5}$, respectively) are in closer proximity to the theoretical values for compounds $\mathbf{4 a}$ and $\mathbf{5 b}$. It seems likely that the isolated regioisomers are structurally similar to $\mathbf{4 a}$ and $\mathbf{5 b}$. Further

\begin{tabular}{|c|c|c|c|}
\hline $\begin{array}{l}\text { Experimental } \\
\text { chemical shift }\end{array}$ & $\begin{array}{c}\text { Calculated chemical } \\
\text { shift }\end{array}$ & Atom number & Compound \\
\hline 48.7 & 48.4 & C-1 & \multirow{2}{*}{$4 a$} \\
\hline 39.0 & 38.7 & $\mathrm{C}-2$ & \\
\hline & 33.2 & $\mathrm{C}-1$ & \multirow{2}{*}{$5 \mathbf{a}$} \\
\hline & 47.5 & $\mathrm{C}-2$ & \\
\hline & 45.2 & $\mathrm{C}-1$ & \multirow{2}{*}{$4 b$} \\
\hline & 31.3 & $\mathrm{C}-2$ & \\
\hline 38.8 & 38.5 & $\mathrm{C}-1$ & \multirow{2}{*}{$5 b$} \\
\hline 50.0 & 49.4 & C-2 & \\
\hline
\end{tabular}
proofs came from activation energy and DFT studies as followings:

Table 1. The comparison of theoretical ${ }^{13} \mathrm{C}$ NMR chemical shifts data $(\delta$, ppm) of C-1 and C-2 of each pair of regioisomers with those obtained from the experimental ${ }^{13} \mathrm{C}$ NMR spectroscopy.

ii) Activation energy calculations

The transition states have been localized for both cyclization modes. The corresponding activation energies and structures are given in Table 2 and Figure 1 respectively. As it can be seen in Table 2, in the reaction between $\mathbf{2 a}$ and $\mathbf{3}$, TS $\mathbf{4 a}$ is located $1.6 \mathrm{kcal}$ below TS $\mathbf{5} \mathbf{a}$ and in the reaction between $\mathbf{2 b}$ and $\mathbf{3}$ TS $\mathbf{5 b}$ is located $0.5 \mathrm{kcal}$ below TS $\mathbf{4 b}$. The activation energies corresponding to the two cyclization modes of the reactions are: $8.5,10.1$ for $\mathbf{2} \mathbf{a}+\mathbf{3}$, and 7.9, 7.2 for $\mathbf{2 b}+\mathbf{3}$. Thus, in $\mathbf{2 a}+\mathbf{3}$ reaction pathway, $\mathbf{4 a}$ regioisomer is kinetically more favored than the $\mathbf{5 a}$. In reaction between $\mathbf{2 b}+\mathbf{3}, 5 \mathrm{~b}$ regioisomer is kinetically more favored than the $\mathbf{4 b}$. The presence of the nitro group in nitrilimine $\mathbf{2 a}$ not only changes the regioselectivity but also slightly increases the barrier. An analysis of the geometries at the TSs given in Figure1 indicates that they correspond to an asynchronous bond formation processes. The extent of bond formation along a reaction pathway is provided by the concept of bond order (BO) ${ }^{28}$. The $\mathrm{BO}$ (Wiberg indexes) values of the $\mathrm{N}-\mathrm{C}$ and $\mathrm{C}-\mathrm{C}$ forming bonds at TSs are shown in brackets in Figure1. These values are within the range of 0.17 to 0.26 . Therefore, it may be suggested that these TSs correspond to early processes. In general, the asynchronicity shown by the geometrical data is accounted for by the BO values. A qualitative reactivity can be estimated by applying Hammond's postulate ${ }^{29}$. All the reactions proceeded exothermically with large $\Delta E_{\mathrm{r}}$ (relative energies between products and reactives) energy values which make them irreversible processes (see Table 2). According to Hammond's postulate, the TSs should then be closer to the reactives. The activation energy values, $\Delta E$, also favor the formation of the cycloadducts $\mathbf{4 a}$ and $\mathbf{5 b}$ against their regioisomers $\mathbf{5 a}$ and $\mathbf{4 b}$ respectively. The polar nature of the two cyclization modes can be estimated by a charge transfer (CT) analysis at the TSs. The CT from nitrilimine $\mathbf{2 a}$ to acrylonitrile $\mathbf{3}$ is 0.19 e at TS $\mathbf{4 a}$ and 0.16 e at TS 5a. Therefore the CT calculations show a NED (normal electron demand) character for this reaction. For $\mathbf{2 b}+\mathbf{3}$, The CT from nitrilimine $\mathbf{2 b}$ to 
acrylonitrile $\mathbf{3}$ is 0.13 e at TS $\mathbf{4 b}$ and 0.17 e at TS $\mathbf{5 b}$. Thus the CT calculations show a NED character for this process.

Table 2. Energies of reactives, transition states and cycloadducts 4 and 5 , $\mathrm{E}$ (a.u.), relative activation energies $\Delta E_{\mathrm{a}}\left(\mathrm{kcal} \mathrm{mol}^{-1}\right)$ relative energies between products and reactives, $\Delta \mathrm{E}_{\mathrm{r}}\left(\mathrm{kcal} \mathrm{mol}^{-1}\right)$ and charge transfer $(\mathrm{CT}$, in e) at TSs

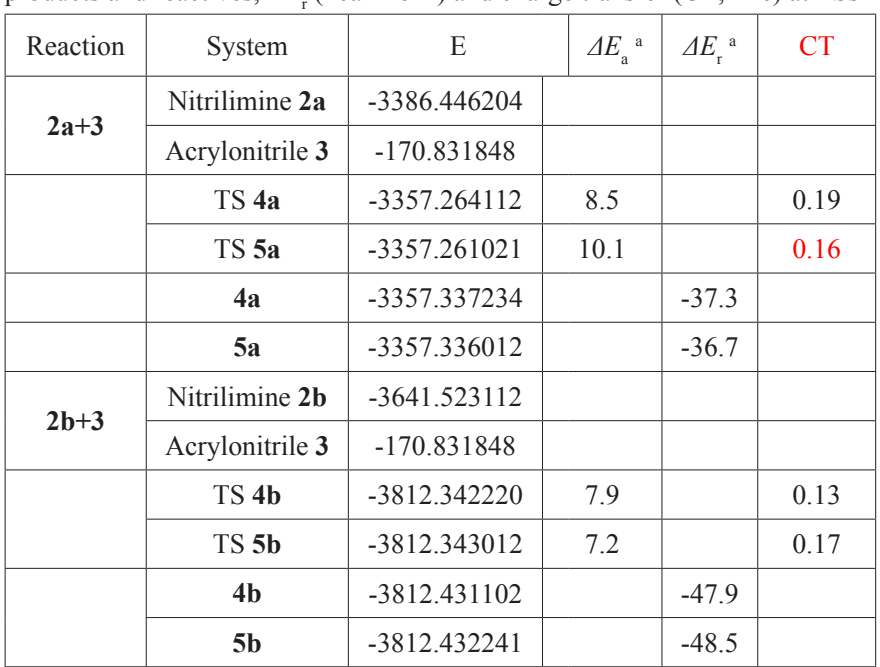

${ }^{a}$ to reactives

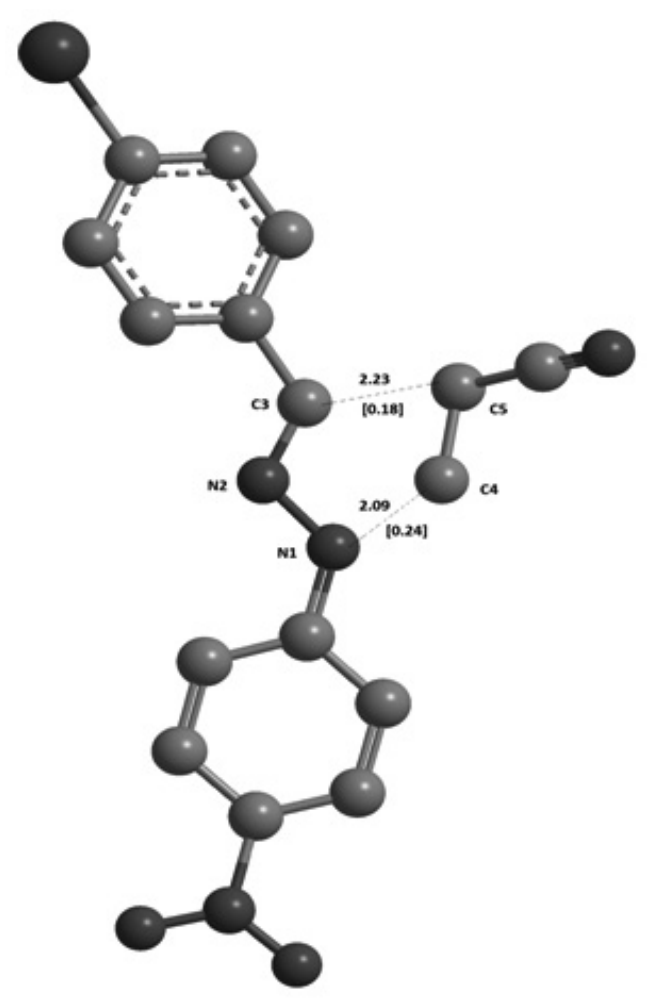

$4(a)$

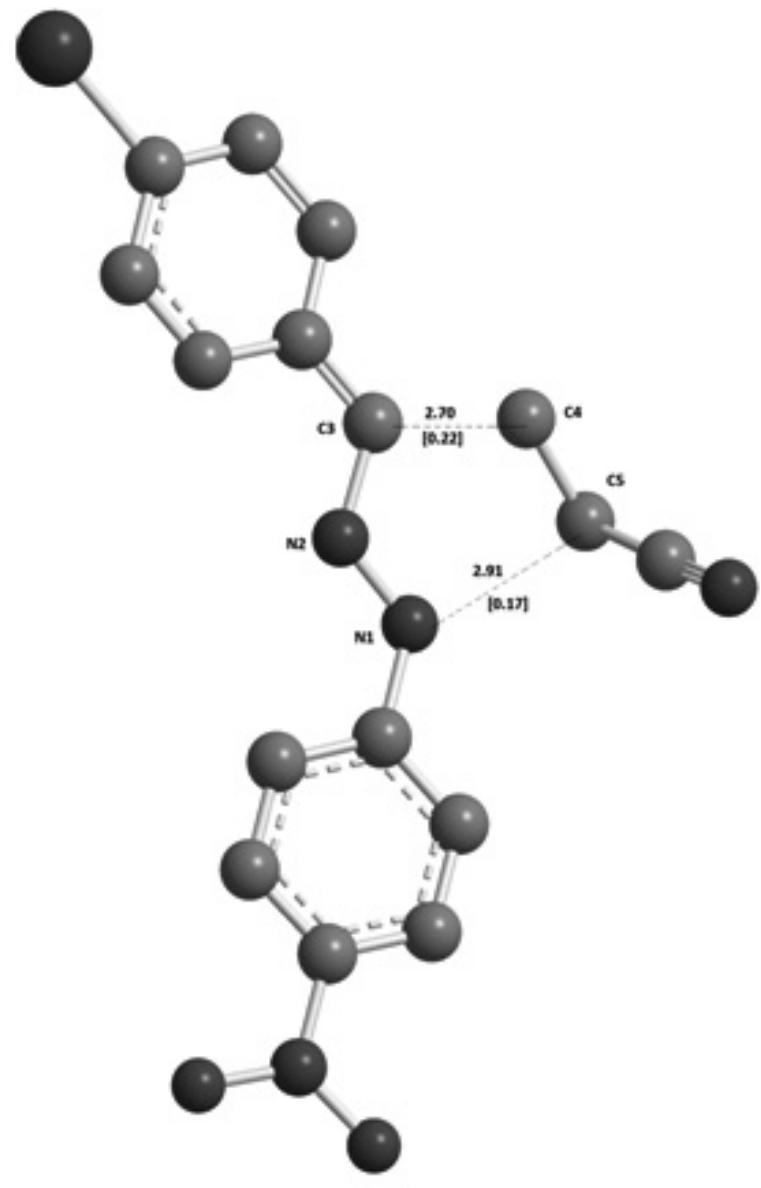

4(b)

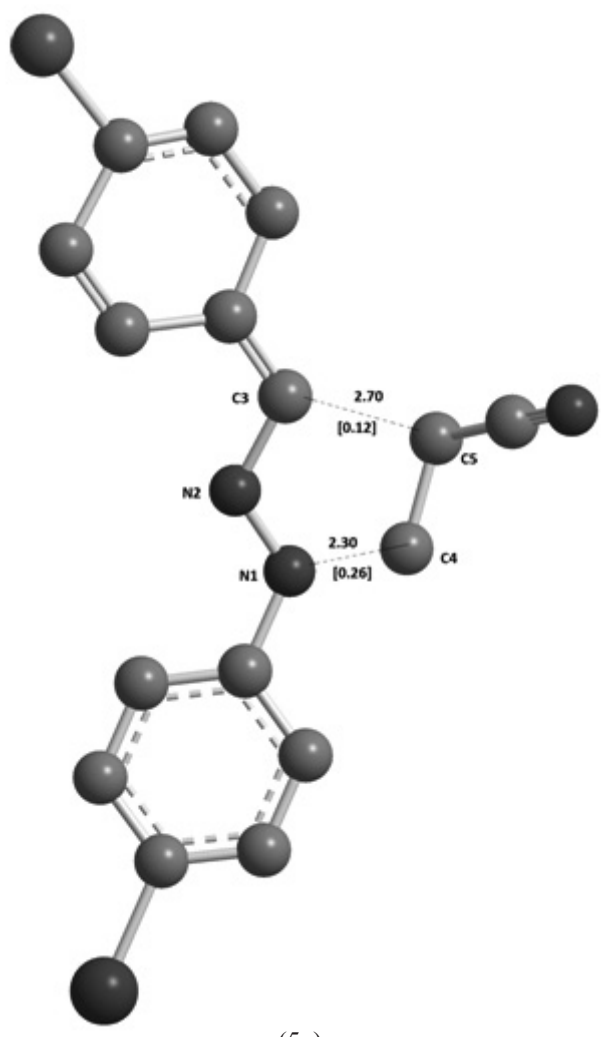

(5a) 


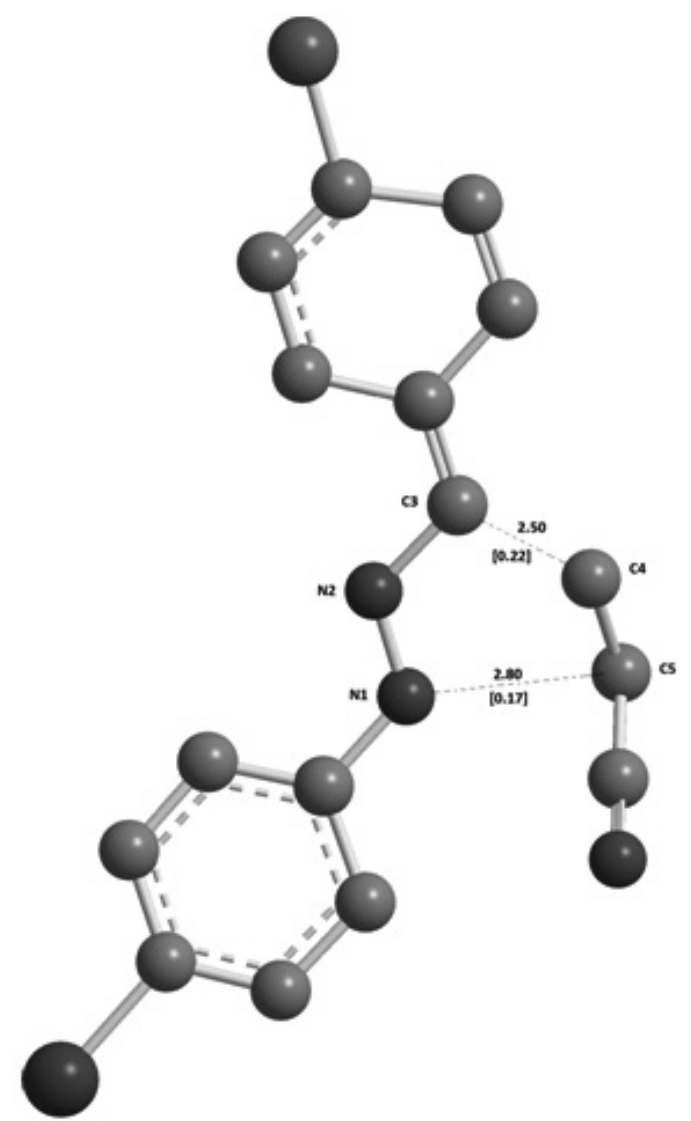

(5b)

Figure 1. Optimized geometries for transition state structures at the B3LYP/6-31G (d) level of theory. Hydrogen atoms have been omitted for clarity. Distances of forming bonds are given in angstroms. The bond orders are given in brackets.

iii) DFT-based reactivity indexes

Prediction of regiochemistry by using DFT-based reactivity indexes

The chemical hardnesses $\eta$, global electrophilicity $w$ and global nucleophilicity $\mathrm{N}$ of the nitrilimines and dipolarophile are given in Table 3. The Fukui indexes for the atoms N1 and $\mathrm{C} 3$ of the dipoles (nitrilimines) and for the atoms $\mathrm{C} 4$ and $\mathrm{C} 5$ of the dipolarophile (acrylonitrile), calculated with MK population analysis, are given in Table 4 (see Scheme 2 for atom numbering).

Table 3. HOMO, LUMO energies in a.u., electronic chemical potential ( $\mu$ in a.u.), chemical hardness ( $\eta$, in a.u.), global electrophilicity $(\omega$, in $\mathrm{eV})$ and global nucleophilicity $(\mathrm{N}$, in $\mathrm{eV})$ for dipole and dipolarophile systems.

\begin{tabular}{|c|c|c|c|c|c|c|}
\hline $\mathrm{N}^{\mathrm{a}}$ & $\omega$ & $\eta$ & $\mu$ & LUMO & HOMO & Reactants \\
\hline 3.416 & 2.309 & 0.126 & -0.146 & -0.083 & -0.210 & $\mathbf{2 a}$ \\
\hline 3.625 & 1.891 & 0.133 & -0.136 & -0.069 & -0.202 & $\mathbf{2 b}$ \\
\hline 1.250 & 1.744 & 0.233 & -0.173 & -0.056 & -0.289 & $\mathbf{3}$ \\
\hline
\end{tabular}

a The HOMO energy of tetracyanoethylene is -0.33514 a.u. at the same level of theory.
Table 4. Fukui indexes for the $\mathrm{N} 1$ and $\mathrm{C} 3$ atoms of the nitrilimines and for atoms $\mathrm{C} 4$ and $\mathrm{C} 5$ of the acrylonitrile

\begin{tabular}{|l|c|c|c|c|c|}
\hline \multirow{2}{*}{ System } & $\begin{array}{c}\text { Atom } \\
\text { number }\end{array}$ & $f_{k}^{+}$ & $f_{k}^{-}$ & $\omega_{\mathrm{k}}$ & $\mathrm{N}_{\mathrm{k}}$ \\
\hline \multirow{2}{*}{ Nitrilimine 2a } & $\mathrm{N} 1$ & & 0.136 & & 0.465 \\
\cline { 2 - 6 } & $\mathrm{C} 3$ & & 0.100 & & 0.340 \\
\hline \multirow{2}{*}{ Nitrilimine 2b } & $\mathrm{N} 1$ & & 0.163 & & 0.591 \\
\cline { 2 - 6 } & $\mathrm{C} 3$ & & 0.215 & & 0.781 \\
\hline \multirow{2}{*}{ Acrylonitrile 3 } & $\mathrm{C} 4$ & 0.359 & & 0.625 & \\
\cline { 2 - 6 } & $\mathrm{C} 5$ & 0.201 & & 0.350 & \\
\hline
\end{tabular}

As it can be seen in Table 3, the electronic chemical potentials of nitrilimines (dipoles) $\mathbf{2 a}$ and $\mathbf{2 b}$ are greater than that of acrylonitrile $\mathbf{3}$ (dipolarophile), which indicates the charge transfer is taking place from nitrilimines to acrylonitrile. Note that even though nitrilimine 2a has a larger electrophilicity value $\mathrm{w}$ than acrylonitrile $\mathbf{3}$, the latter has a lower chemical potential, which is the index that determines the direction of the electronic flux along the cycloaddition. These results are in agreement with $\mathrm{CT}$ calculations at the TSs. For better visualization we have depicted these interactions in Scheme 2. In the reaction between $\mathbf{2 a}$ and $\mathbf{3}$, the most favorable two-center interaction takes place between $\mathrm{N} 1$ of nitrilimine 2a and $\mathrm{C} 4$ of the acrylonitrile $\mathbf{3}$ leading to the formation of the $\mathbf{4 a}$ regioisomer. In the reaction between $\mathbf{2 b}$ and $\mathbf{3}$, the most favorable two-center interaction takes place between $\mathrm{C} 3$ of nitrilimine $\mathbf{2 b}$ and $\mathrm{C} 4$ of the acrylonitrile $\mathbf{3}$ leading to the formation of the $\mathbf{5 b}$ regioisomer. The replacement of $\mathrm{Br}$ group in $\mathbf{2} \mathbf{b}$ (or $\mathbf{5} \mathbf{b}$ in Scheme 2) by $\mathrm{NO}_{2}$ in $\mathbf{2 a}$ (or $\mathbf{4 a}$ in Scheme 2) changes the $\mathrm{N} 1$ and $\mathrm{C} 3$ values. This fact is the responsible for the changes in the calculated regioselectivity. As it can be seen in Scheme 2, the local philicity indexes $\left(\omega_{k}, N_{k}\right)$ seem to be a reliable tool for the prediction of the most favored interaction in a two-center polar process. It turns out that the two-center polar model, based on electrostatic charges, predicts correctly the experimental regioselectivity.

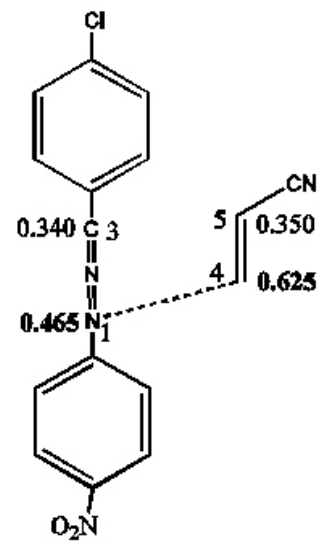

4a

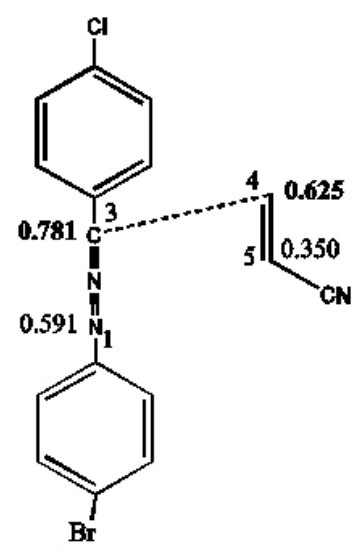

sb
Scheme 2. Illustration of the favorable interactions using Local nucleophilicities, $N_{k}$, for dipole centers and local electrophilicities, $\omega_{k}$, for the acrylonitrile centers calculated with MK population analysis.

In conclusion the regioselectivity for the 1,3-DC reactions of nitrilimines $\mathbf{2}$ with acrylonitrile $\mathbf{3}$ has been investigated using experimental and theoretical ${ }^{13} \mathrm{C}$ NMR studies together with the activation energy calculations and the DFT-based reactivity indexes at the B3LYP/6-31G(d) level of theory. The results obtained in this work clearly predict the regiochemistry of the isolated cycloadducts. 


\section{REFERENCES}

1. K.V. Gothelf, K.A. Jorgensen, Chem. Rev. 98 (1998) 863.

2. A. Padwa, A. 1,3-Dipolar Cycloaddition Chemistry; Wiley: New York, 1984.

3. A.Wasserman Diels-Alder Reactions; Elsevier: NewYork, 1965.

4. I. Fleming Pericyclic Reactions; Oxford University: Oxford, 1999.

5. G. Krajsovszky, A. N. Haider, J. Mol. Struc (Theochem) 528 (2000) 13

6. G. Molteni, A. Ponti, J. Org. Chem. 66 (2001) 5252.

7. G. Molteni, A. Ponti, Tetrahedron 59 (2003) 5225.

8. G. Molteni, ARKIVOC ii (2007) 224.

9. K. Wolinski, J.F. Hilton and P. Pulay, J. Am. Chem. Soc. 112 (1990) 8251

10. A. Garc'1a-Granados, E. Melguizo and A. Parra, J. Org. Chem. 65 (2000) 8214.

11. L. R. Domingo, M. J. Aurell, P. Pérez and R. Contreras, Tetrahedron 58 (2002) 4417.

12. P. Pérez, L. R. Domingo, M. J. Aurell and R. Contreras, Tetrahedron 59 (2003) 3117.

13. L. R. Domingo, E. Chamorro, P. Pérez, J. Org. Chem. 73 (2008) 4615.

14. L. R. Domingo, M. J. Aurell, P. Pérez and R. Contreras, J. Phys. Chem. A 106 (2002) 6871.

15. G. Bentabed-Ababsa, A. Derdour, T. Roisnel, J. A. Sa'ez, P. Pe'rez, E. Chamorro, L. R. Domingo and F. Mongin, J. Org. Chem. 74 (2009) 2120.

16. M. J. Frisch, G. W. Trucks, H. B. Schlegel, G. E. Scuseria, M. A. Robb, J. R. Cheeseman, J. A. Montgomery, T. Vreven, K. N. Kudin, J. C. Burant,; J. M. Millam, S. S. Iyengar, J. Tomasi, V. Barone, B. Mennucci, M. Cossi, G. Scalmani, N. Rega, G. A. Petersson, H. Nakatsuji, M. Hada, M. Ehara, K. Toyota, R. Fukuda, J. Hasegawa, M. Ishida, T. Nakajima, Y. Honda,
O. Kitao, H. Nakai, M. Klene, X. Li, J. E. Knox, H. P. Hratchian, J. B. Cross, V. Bakken, C. Adamo, J. Jaramillo, R. Gomperts, R. E. Stratmann, O. Yazyev, A.J. Austin, R. Cammi, C. Pomelli, J. W. Ochterski, P. Y. Ayala, K. Morokuma, G. A. Voth, P. Salvador, J. J. Dannenberg, V. G. Zakrzewski, S. Dapprich, A. D. Daniels, M. C. Strain, O. Farkas, D. K. Malick, A. D. Rabuck, K. Raghavachari, J. B. Foresman, J. V. Ortiz, Q. Cui, A. G. Baboul, S. Clifford, J. Cioslowski, B. B. Stefanov, G. Liu, A. Liashenko, P. Piskorz, I. Komaromi, R. L. Martin, D. J. Fox, T. Keith, M. A. Al-Laham, C. Y. Peng, A. Nanayakkara, M. Challacombe, P. M. W. Gill, B. Johnson, W. Chen, M. W. Wong, C. Gonzalez and J. A. Pople, GAUSSIAN 98, Revision A.7; Gaussian: Wallingford, CT, 1998.

17. H. B. Schlegel, J. Comput. Chem. 3 (1982) 214.

18. U. C. Singh, P. A. Kollman, J. Comput. Chem. 5 (1984) 129.

19. B. H. Besler, K. M. Merz and P. A. Kollman, J. Comput. Chem. 11 (1990) 431.

20. R. G. Parr, L. V. Szentpály and S. Liu, J. Am. Chem. Soc. 121 (1999) 1922.

21. R. G. Parr, W. Yang, Density Functional Theory of Atoms and Molecules, Oxford University Press: New York, 1989.

22. R. G. Parr, R. G. Pearson, J. Am. Chem. Soc. 105 (1983) 7512.

23. W. Yang, W.J. Mortier, J. Am. Chem. Soc. 108 (1986) 5708.

24. K. Fukui, Science 218 (1982) 747.

25. R. G. Parr, W. Yang, J. Am. Chem. Soc. 106 (1984) 4049.

26. P. Pérez, L. R. Domingo, M. Duque-Noreña, E. Chamorro, J. Mol. Struc. (Theochem) 895 (2009) 86.

27. R. Huisgen, M. Seidel, G. Wallbillich and H. Knupffer, Tetrahedron 17 (1962) 3 .

28. K. B. Wiberg, Tetrahedron 24 (1968) 1083.

29. G. S. Hammond, J. Am. Chem. Soc. 77 (1955) 334 